\title{
Essentializing Language and the Prospects for Ameliorative Projects ${ }^{1}$
}

\author{
Katherine Ritchie \\ University of California, Irvine \\ Forthcoming in Ethics
}

\begin{abstract}
Some language encourages essentialist thinking. While philosophers have largely focused on generics and essentialism, I argue that nouns as a category are poised to refer to kinds and to promote representational essentializing. Our psychological propensity to essentialize when nouns are used reveals a limitation for anti-essentialist ameliorative projects. Even ameliorated nouns can continue to underpin essentialist thinking. I conclude by arguing that representational essentialism does not doom anti-essentialist ameliorative projects. Rather it reveals that would-be ameliorators ought to attend to the propensities for our representational devices to essentialize and to the complex relationship between essentialism and prejudice.
\end{abstract}

Key Words: essentialism, anti-essentialism, nouns, generics, ameliorative projects, conceptual engineering

Some language encourages essentialist thinking. It promotes viewing categories as homogenous, explanatory, and inductively potent, and viewing category membership as determined by underlying hidden "essences". By showing that nouns and their conceptual correlates are poised to essentialize, I argue that the prospects for certain political and social justice-oriented conceptual engineering projects are put at risk. When engaged in conceptual engineering one asks what concepts or linguistic expressions we ought to use and then advocates for revising, replacing, or abandoning our mental and linguistic resources accordingly. ${ }^{2}$ The continued use of nouns, even with re-engineered contents, can undermine the success of conceptual engineering projects which have anti-essentialist

\footnotetext{
${ }^{1}$ I thank participants at the Fifth Meeting of the ConceptLab workshop in Zermatt, the Rutgers Feminist Philosophy Reading Group, the CUNY Faculty Fellowship Publishing Program, the 2019 Banff Conference on Essentialism and Anti-Essentialism, colloquia at Mount Holyoke, Rice University, and Duke University, and at meetings of the Group for Empirical Approaches to Morality and Society and the Barcelona Social Metaphysics Seminar for helpful feedback. In particular, I thank Mark Balaguer, Rebecca Chan, Nina Emery, Sally Haslanger, Ned Markosian, Kathrin Koslicki, Ari Koslow, Rebecca Mason, Michaela McSweeney, Esther Rosario, Jack Spencer, Rachel Sterken, Amie Thomasson, and two anonymous referees and two anonymous members of the editorial board at Ethics for comments that improved the paper. Support for this project was provided by a PSC-CUNY Award, jointly funded by The Professional Staff Congress and The City University of New York.

2 While this is a widely held view of conceptual engineering (or what is sometimes called "conceptual ethics" or "ameliorative projects"), it is not uncontroversial. For dissent see, e.g., Herman Cappelen, Fixing Language: An Essay on Conceptual Engineering. (Oxford: Oxford University Press, 2018). For discussions of conceptual engineering see Alexis Burgess and David Plunkett, "Conceptual Ethics I," Philosophy Compass 8, no. 12 (2013): 1091-1101; Alexis Burgess and David Plunkett, "Conceptual Ethics II,” Philosophy Compass 8, no. 12 (2013): 1102-1110; Cappelen Fixing Language; and the papers in Alexis Burgess, Herman Cappelen, and David Plunkett, eds., Conceptual Engineering and Conceptual Ethics (Oxford: Oxford University Press, 2020).
} 
aims. Would-be ameliorators ought to attend to the propensities for our representational devices to essentialize and to the complex relationship between essentialism and prejudice.

To begin to see the difference between the essentializing effects of adjectives and nouns consider the following pairs of sentences:

1. a. Adrianne is female.

b. Adrianne is a female.

2. a. Dante is queer.

b. Dante is a queer.

3. a. Lorraine is blonde.

b. Lorraine is a blonde.

4. a. Maria is Mexican.

b. Maria is a Mexican.

While the sentences differ minimally, you might have noticed a significant difference in their cognitive effects. The $b$ sentences, which include predicate nominals, label or classify the subject. They invite thoughts that there are further shared, stable, and explanatory features of the group or kind. They may also bring to mind stereotypes about the social kind. For instance speakers of $2 \mathrm{~b}$ might be taken to imply that there are behavioral, psychological, or normative characteristics that queer people share. In contrast the $a$ sentences, which include predicate adjectives, do not seem to convey that the subject belongs to a kind or group that is explanatorily significant. They do not encourage the same sorts of stereotypical generalizations as the $b$ sentences. These examples suggest a connection between lexical/conceptual categories, on the one hand, and essentializing, on the other.

Here I argue that the vehicles of representation ought be taken into consideration when designing linguistic and conceptual prescriptions. In defining conceptual ethics, Burgess and Plunkett note that " $[\mathrm{t}]$ he phrase ... trains our attention on content rather than form, suggesting that the structures or vehicles of representation are ethically irrelevant." 3 They disavow the implication and note that this is merely a terminological shortcoming. The way nominal constructions, like in $1 \mathrm{~b}-4 \mathrm{~b}$ above, elicit essentialist thinking provides a concrete case to show why. Anti-essentialist ameliorative projects can fail to meet their chief social and political end by failing to consider vehicles of representation.

The paper proceeds as follows. First, I set out our target class of conceptual engineering projects-anti-essentialist ameliorative projects-and clarify what essentialism and anti-essentialism

\footnotetext{
3 Burgess and Plunkett, “Conceptual Ethics II”, 1094 emphasis original.
} 
amount to $(\mathbb{I})$. Then I use data from semantics and cognitive and developmental psychology to argue that the difference in the essentializing effects of nouns and adjectives is robust (\$II). While much of the discussion of language and essentialism has focused on generics, ${ }^{4} \mathrm{I}$ argue that essentialist language goes far beyond constructions like 'women are nurturing'. I focus on predicate nominals like those in $1 \mathrm{~b}-4 \mathrm{~b}$, but gesture towards the more general view that it the lexical category, nouns, that is poised to elicit essentialist thinking. Next I argue that given our psychological tendency to essentialize, the prospects for anti-essentialist ameliorative projects are undermined when nouns are retained $(\mathscr{I I I})$. Finally I consider two responses for the would-be ameliorator $(\mathscr{I} I V)$. I argue that an eliminativist strategy faces significant normative and implementation worries. I then suggest that a more nuanced strategy that involves a distinction between pernicious and non-pernicious essentializing be pursued. The interplay between prejudice, identity, and essentialism point to defeasible constraints the ameliorator can use to guide her projects. Ameliorators ought to attend to our psychological propensities, but representational essentialism need not doom ameliorative projects.

\section{Anti-Essentialism and Ameliorative Projects}

Conceptual engineering projects come in varied forms. Our focus is on a class of projects that involve (a) advocating for the use of some concepts or expressions and (b) designing new conceptual or linguistic content for the purpose of achieving political or social justice aims. I'll call this restricted class of conceptual engineering projects ameliorative projects.

Not all conceptual engineering is ameliorative. Some conceptual engineers aim to improve our understanding of terms or concepts, rather than working to change our representational devices. 5 Other conceptual engineers propose that a concept or expression be abandoned. In

\footnotetext{
${ }^{4}$ For example, see Sally Haslanger, "Ideology, Generics, and Common Ground," in Feminist Metaphysics, ed. Charlotte Witt (Dordrecht: Springer-Verlag, 2011), 179-207; Marjorie Rhodes, Sarah-Jane Leslie, and Christina M. Tworek, "Cultural Transmission of Social Essentialism," PNAS Proceedings of the National Academy of Sciences of the United States of America 109, no. 34 (2012): 13526-13531; Emily Foster-Hanson, Sarah-Jane Leslie, and Marjorie Rhodes, "How Does Generic Language Elicit Essentialist Beliefs?," in Proceedings of the 38th Annual Conference of the Cognitive Science Society, eds. Anna Papafragou, Daniel Grodner, Daniel Mirman and John C. Trueswell (Austin, TX: Cognitive Science Society, 2016), 1541-1546; Sarah-Jane Leslie, “The Original Sin of Cognition: Fear, Prejudice, and Generalization," Journal of Philosophy 114, no. 8 (2017): 393-421; Daniel Wodak, Sarah-Jane Leslie, and Marjorie Rhodes, "What a Loaded Generalization: Generics and Social Cognition,” Philosophy Compass 10, no. 9 (2015): 625-635.

${ }_{5}^{5}$ In recent work Haslanger categorizes projects that involve augmenting our understanding the content of a concept as epistemic ameliorative projects. She contrasts them with informational/semantic ameliorative projects, which involve changing concepts or expressions themselves, rather than our epistemic access to their contents. The ameliorative projects focused on here are semantic. See Sally Haslanger, "Going On, Not in the Same Way," in Conceptual Engineering and Conceptual Ethics, eds. Alexis Burgess, Herman Cappelen, and David Plunkett (Oxford: Oxford University Press, 2020), 230-260.
} 
contrast, ameliorative projects involve advocating for the use of representational devices with new content. This could come in the form of retaining and revising extant concepts or introducing and championing new representational devices (i.e., new pronouns like ze and zir). Not all conceptual engineering projects have political or social justice aims. For instance, a project might focus solely on making expressions more exact in the service of clearer scientific explanations. Since such a project fails to meet (b) in the definition above, it is not ameliorative in the way I use the expression. ${ }^{6}$

The sorts of social political aims an ameliorative project might have are likewise diverse. Broadly speaking they are aimed at mitigating oppression and breaking down power structures. One way to do so is through debunking the view that a kind is natural. They might also engage in efforts to construct identities and promote solidarity. And some ameliorative projects have anti-essentialist aims. Anti-essentialists argue that there is no shared essence of, e.g., all and only women. My focus here is on ameliorative projects with anti-essentialist aims.

Ameliorative accounts have been proposed for concepts of gender, sexual orientation, race, and other social categories. ${ }^{7}$ In order to work with a concrete illustration of an ameliorative project, I focus on Haslanger's theory of gender. ${ }^{8}$ The argument made here is not specific to her account. Rather, it reveals a general way that anti-essentialist ameliorative projects need to consider the propensities for representational devices to essentialize when working to meet anti-essentialist ends.

Haslanger argues for a revisionary view of gender and gender terms and concepts. She proposes the following as a first pass definition:

$\mathrm{S}$ is a woman iff $\mathrm{df} \mathrm{S}$ is systematically subordinated along some dimension (economic, political, legal, social, etc.) and S is "marked" as a target for this treatment by observed or imagined bodily features presumed to be evidence of a female's biological role in reproduction.?

She offers similar definitions for man (substituting privilege and male's in the relevant places) and for racial groups (with substitutions based on presumed ancestry). She states that her project is semantic — she is proposing definitions and "asking us to use an old term in a new way" and that it is political

\footnotetext{
${ }^{6}$ For discussion of different sorts of ameliorative projects and aims see Haslanger "Going on, Not in the Same Way".

7 For example see Sally Haslanger, "Gender and Race: (What) are They? (What) Do We Want Them To Be?,” Noûs 34 (2000): 31-55; Sally Haslanger, Resisting Reality: Social Construction and Social Critique. (Oxford: Oxford University Press, 2012); Robin Dembroff, "What is Sexual Orientation?," Philosophers' Imprint. 16, no. 3 (2016); Robin Dembroff, "Beyond Binary: Genderqueer as Critical Gender Kind,” Philosophers' Imprint. 20, no. 9 (2020): 1-23; Katharine Jenkins, "Amelioration and Inclusion: Gender Identity and the Concept of Woman," Ethics 126 (2016): 394-421.

${ }^{8}$ Haslanger, "Gender and Race" and Haslanger, Resisting Reality.

${ }^{9}$ Haslanger, "Gender and Race”, 39.
} 
as she's "asking us to understand ourselves and those around us as deeply molded by injustice and to draw on the appropriate prescriptive inference." 10 Her project is ameliorative.

At some points Haslanger discusses social constructionist projects as revelatory rather than revisionary. For instance in a later article she says that rather than proposing a revised meaning a social constructionist might "reveal an existing one."11 Cappelen criticizes the view saying "amelioration as revelation undermines the basic idea behind ameliorative projects" as it ends up being "essentially a purely descriptive project. the aim is to figure out what the extensions really are."12 The revelatory project isn't revisionary and, so, is not ameliorative in the sense that I am using the term. Given the more revisionist things she says at other points, there is at least one reasonable interpretation of Haslanger's account on which it is ameliorative. I'll interpret the view in that way for the purposes of this paper. ${ }^{13}$

Haslanger has several social political goals in giving an account of gender and race. She states that a framework needs to be "sensitive to both the similarities and differences among males and females, and the similarities and differences among individuals in groups demarcated by 'color'; this includes the concern to identify the effects of interlocking oppressions." 14 A framework's being sensitive to differences involves avoiding what Haslanger calls the Commonality Problem, which questions whether there is anything social that all women have in common, that is, whether there is an essence shared by all women. Anti-essentialism is one political aim guiding her ameliorative project.

In order to better understand anti-essentialism and, ultimately, to see the problem that reliance on certain representation types poses for anti-essentialist ameliorative projects, we need to first get clearer on what essentialism is. Essentialism is used to pick out two classes of views-one about representations and one about the world itself. Metaphysical essentialism is the view that entities (e.g., individuals, events, or kinds) have underlying essences. For instance the chemical kind water

\footnotetext{
10 Ibid., 48.

11 Sally Haslanger, “What Good are Our Intuitions?”' Aristotelian Society Supplementary 80, no. 1 (2006): 89-118, 110.

12 Cappelen, Fixing Language, 80 emphasis original.

${ }^{13}$ For further discussion see Elizabeth Barnes, "Gender and Gender Terms," Noûs 54, no. 3 (2020): 704-730; Esa DíazLeón, "Woman as a Politically Significant Term: A Solution to the Puzzle," Hypatia 31 (2016): 245-58; Haslanger, "Going On, Not in the Same Way."

14 Haslanger, "Gender and Race”, 36.
} 
might have the underlying essence of being composed of $\mathrm{H}_{2} \mathrm{O} .{ }^{15}$ Essences in the metaphysical sense might be understood in terms of metaphysically necessary features, grounds, fundamentality, or real definitions. ${ }^{16}$

Representational essentialism is the view that some of our linguistic and mental devices (e.g., words, concepts) represent categories (or individuals) as having hidden underlying essences that determine category membership (or identity) and explain or cause other observable properties. The psychologist Susan Gelman describes representational essentialism as having two related components-one about kinds, the other about essences. The kind component is that "people treat certain categories as richly structured 'kinds' with clusters of correlated properties."17 The essence component is that "people believe a category has an underlying property (essence) that cannot be observed directly but that causes the observable qualities that category members share."18 Psychological research supports both components. ${ }^{19}$

\footnotetext{
15 Saul Kripke, Naming and Necessity (Cambridge, MA: Harvard University Press, 1980); Hilary Putnam, "The Meaning of 'Meaning'," in Language, Mind, and Knowledge, (Minnesota Studies in the Philosophy of Science 7), ed. Keith Gunderson (Minneapolis, Minnesota: University of Minnesota Press, 1975), 131-193.
}

${ }^{16}$ Kit Fine, "Essence and Modality," Philosophical Perspectives 8 (1994): 1-16; Jonathan Schaffer, "On What Grounds What," in Metametaphysics, eds. David Chalmers, David Manley, and Ryan Wasserman (Oxford: Oxford University Press, 2009), 347-283; Gideon Rosen, "Metaphysical Dependence: Grounding and Reduction," in Modality: Metaphysics, Logic, and Epistemology, eds. Robert Hale and Aviv Hoffman (Oxford: Oxford University Press, 2010), 109-136.

${ }_{17}$ Susan A. Gelman, "Psychological Essentialism in Children," Trends in Cognitive Sciences 8, no. 9 (2004): 404-409, 408.

18 Ibid., 408. Both of these assumptions might be represented in ways that are unconscious or implicit. See Douglas L. Medin and Andres Ortony, "Psychological Essentialism," in Similarity and Analogical Reasoning, eds. Stella Vosniadou and Andrew Ortony (New York, NY: Cambridge University Press, 1989), 179-195; Sarah-Jane Leslie, "Essence and Natural Kinds: When Science Meets Preschooler Intuition," Oxford Studies in Epistemology 4 (2013): 108-165. For instance, Leslie argues that we might "rarely, if ever, explicitly entertain thoughts about [essence] as such; rather, [our essentialist] beliefs are tacit or implicit, though they are frequently manifested in a number of explicit ways.” Ibid., 110.

${ }^{19}$ How to understand cognition, language, and the interaction between them are each immense topics on which there is no broad consensus. For arguments against psychological essentialism and in favor of an account relying on representations of causal laws, see Michael Strevens, "The Essentialist Aspect of Naive Theories," Cognition 74 (2000): 149-175. For an alternative way of understanding mental and linguistic representation in terms of conceptual models, imagistic schemas, and metaphorical mappings, see George Lakoff and Mark Johnson, Metaphors We Live By (Chicago: University of Chicago Press, 1980); George Lakoff, Women, Fire, and Dangerous Things: What Categories Reveal about the Mind. (Chicago: University of Chicago Press, 1987a); George Lakoff, "Cognitive Models and Prototype Theory," in Concepts and Conceptual Development: Ecological Conceptual Factors in Categorization, ed. Ulric Neisser (Cambridge: Cambridge University Press, 1987b), 63-100. 
Kinds are represented as having a number of important features. ${ }^{20}$ They are taken to be cohesive and to have inductive potential. Membership in kinds is taken to be relatively stable and is often taken to be exclusive. People also take kinds to figure in certain forms of explanation. And, importantly, these features hold of our representations of social kinds, like races and genders, as well as kinds like tigers and dogs. ${ }^{21}$

Existing research shows that we represent some kinds as having hidden internal essences that determine kind membership. ${ }^{22}$ In much of the psychological research essences are taken to be innate, biological, and fixed at the origin of birth. ${ }^{23}$ However, work on dual character concepts and essence, suggests that kinds might also have natural or evaluative essences. For instance, the essence of an artist might be to realize one's creativity by creating works with aesthetic value. ${ }^{24}$

Recent work has sought to further distinguish and clarify the relationship between representing a category as a kind and as having an essence. ${ }^{25}$ Here, I adopt Gelman's view of representational essentialism as involving both kind and essence components for two reasons. First,

${ }^{20}$ Ellen M. Markman, Categorization and Naming in Children: Problems of Induction (Cambridge, MA: MIT Press, 1989); Myron Rothbart and Marjorie Taylor, "Category Labels and Social Reality: Do We View Social Categories as Natural Kinds?," in Language, Interaction and Social Cognition, eds. Gün R. Semin and Klaus Fiedler (London: Sage:, 1992), 11-36; Susan A. Gelman, The Essential Child: Origins of Essentialism in Everyday Thought. (New York, Oxford University Press, 2003); Gelman, "Psychological Essentialism in Children"; Sandeep Prasada and Elaine M. Dillingham, "Principled and Statistical Connections in Common Sense Conception," Cognition 99, no. 1 (2006): 73-112; Sandeep Prasada and Elaine M. Dillingham, "Representation of Principled Connections: A Window Onto the Formal Aspect of Common Sense Conception,” Cognitive Science 33 (2009): 401-448; Sandeep Prasada, Laura Hennefield, and Daniel Otap, "Conceptual and Linguistic Representations of Kinds and Classes," Cognitive Science 36, no. 7 (2012): 1224 - 1250 ; Alexander Noyes and Yarrow Dunham, "Separating Kindhood from Naturalness: Kinds are Diverse in Causal Structure," (under review). Online at: https://psyarxiv.com/q3zg5/.

${ }^{21}$ For example, Rothbart and Taylor, "Category Labels and Social Reality."

22 Markman, Categorization and Naming in Children; Gelman, The Essential Child; Marjorie Rhodes and Susan A. Gelman, "A Developmental Examination of the Conceptual Structure of Animal, Artifact, and Human Social Categories across Two Cultural Contexts. Cognitive Psychology, 59 (2009): 244-274.

23 See Gelman, "Psychological Essentialism in Children," and citations therein.

${ }^{24}$ For arguments that there are biological and evaluative essences see George E. Newman and Joshua Knobe, "The Essence of Essentialism," Mind and Language 34, no. 5 (2019): 585-605. For related discussions and experiments on dual character concepts see Joshua Knobe, Sandeep Prasada, George E. Newman, "Dual character concepts and the normative dimension of conceptual representation," Cognition 127, no. 2 (2013): 242-257. For experiments showing similarities between judgments involving kinds that are taken to have natural (e.g., biological or chemical) essences and kinds that have evaluative essences, see Kevin P. Tobia, George E. Newman, and Joshua Knobe, "Water is and is not $\mathrm{H}_{2} \mathrm{O}$," Mind and Language 35, no. 2 (2020): 183-208.

25 Nick Haslam, Louis Rothschild, and Donald Ernst, Essentialist Beliefs about Social Categories. British Journal of Social Psychology 39, no. 1 (2000): 113-127; Noyes and Dunham, "Separating Kindhood from Naturalness"; Katherine Ritchie and Joshua Knobe, "Kindhood and Essentialism: Evidence from Language," in Advances in Child Development and Behavior 59, ed. Marjorie Rhodes (Cambridge, MA: Elsevier, 2020), 133-164. 
there is extensive precedent in the psychological literature for doing so. Second, and more importantly for our purposes, anti-essentialist arguments have targeted both.

Anti-essentialism as a view in critical theory is plausibly understood as an at least partially metaphysical, rather than representational, thesis. In the example that we are considering, it involves the claim that there is no underlying category-determining features shared by all and only women. Appiah argues that “in general, there isn't some inner essence that explains why people of a certain identity are the way they are." 26 Here he is arguing that there fails to be an essence underlying race, gender, ethnicity, and so on. He isn't claiming that people do not believe that there are underlying essences.

Haslanger's response to the Commonality Problem is also construed in metaphysical terms. She argues that a social kind with a contextually sensitive social positional nature fails to attribute an essence to kind members in the way that positing a biological or psychological essence of the kind would. Moreover, shared social position allows for significant variation. So, Haslanger argues that the view avoids the problem and meets the aims that anti-essentialism requires. ${ }^{27}$ This understanding of anti-essentialism requires us to engage in social metaphysics.

A proponent of anti-essentialism in metaphysics can reject metaphysical essentialism, while accepting that it is an unfortunate fact that representational essentialism is true. For instance while arguing for anti-essentialism and intersectionality as tools for dismantling oppressive power structures, Grillo states "We all have the impulse to essentialize. It is built into our brains." 28 This does not mean that representational essentialism is of no concern to anti-essentialist theorists. Rather, as Grillo argues, we need to attend to the ways we essentialize in order to use anti-oppressive tools successfully. Applied to ameliorative projects, we need to attend to our psychological propensity to essentialize when designing and implementing social justice tools. Would-be ameliorators must grapple with representational essentialism in ways that one solely concerned with offering metaphysical analyses need not. To better see how anti-essentialists have engaged with representational essentialism, let's next consider the prominent motivations for anti-essentialism.

Some anti-essentialist arguments single out the assumption that there is a bidden and intrinsic essence to a category-that is, they target the essence component of representational essentialism. Many of these arguments target the view that there is a biological essence underlying gender, racial,

\footnotetext{
${ }^{26}$ Kwame Anthony Appiah, The Lies that Bind: Rethinking Identity (New York: Liveright, 2018), 29.

${ }^{27}$ cf. Jenkins, "Amelioration and Inclusion" for arguments that the account fails to include trans women.

28 Trina Grillo, “Anti-Essentialism and Intersectionality: Tools to Dismantle the Master's House,” Berkeley Women's Law Journal. 10, no. 1 (1995): 16-30, 28.
} 
and other categories. For instance Witt calls the argument against a natural essence "the core argument" against kind essentialism. ${ }^{29}$ And Stone states "feminist thinkers often use 'essentialism' and 'biological essentialism' as interchangeable terms."30 Yet, anti-essentialist concerns go beyond arguments against biological or psychological essences. Cultural essences or other social essences determining kind membership are no less essences than those requiring particular chromosomes or genitalia. 31

Other feminist anti-essentialist arguments target features that are associated with the kindhood component of representational essentialism. For instance, psychological research shows that inductive generalization is connected to kindhood. ${ }^{32}$ Gender essentialism has been criticized for leading to overgeneralizations. These are problematic not just in virtue of being false but, as Narayan argues, "these generalizations are hegemonic in that they represent the problems of privileged women (most often white, Western, middle-class, heterosexual women) as paradigmatic 'women's issues."'33

Stability, another feature associated with the kind component of representational essentialism, has also been objected to on anti-essentialist grounds. Grillo argues that essentialism assumes "being a member of the group under discussion is a stable one, one with a clear meaning, a meaning constant through time, space, and different historical, social, political, and personal contexts." 34 In arguing that gender is constituted by performance, Butler argues gender is not "a stable identity" 35 and that there is no "essential and unrealized 'sex' or 'gender." 36 Essentialism has

\footnotetext{
${ }^{29}$ Charlotte Witt, “Anti-Essentialism in Feminist Theory,” Philosophical Topics 23, no. 2 (1995): 321-344.

30 Alison Stone, "Essentialism and Anti-Essentialism in Feminist Philosophy," Journal of Moral Philosophy 1, no. 2 (2004): 135-153, 138.

31 Witt, "Anti-Essentialism in Feminist Theory"; Stone, "Essentialism and Anti-Essentialism"; Uma Narayan, "Essence of Culture and a Sense of History: A Feminist Critique of Cultural Essentialism,” Hypatia 13, no. 2 (1998): 86-106.

32 Rothbart and Taylor, "Category Labels and Social Reality"; Gelman, "Psychological Essentialism in Children"; Noyes and Dunham, "Separating Kindhood from Naturalness."

${ }^{33}$ Narayan, "Essence of Culture," 86.

34 Grillo, “Anti-Essentialism and Intersectionality,” 19.

35 Judith Butler, "Performative Acts and Gender Constitution: An Essay in Phenomenology and Feminist Theory,"

Theatre Journal 40, no. 4 (1988): 519-531, 519.

36 Ibid., 527.
} 
been objected to given that what is taken to be required for membership in a gender group (or racial group or ...) has varied significantly across time and place, as well as within a culture. ${ }^{37}$

Finally, anti-essentialist arguments that rely on intersectionality also target another feature related to kindhood-exclusive membership. Anti-essentialist intersectional theorists argue that the attempt to subtract other forms of oppression "elevates white, middle-class experience into the norm, making it the prototypical experience."38 Focusing on gender obscures the way that various forms of oppression (e.g., that due to class, race, ethnicity, sexuality, disability, and so on) intersect in ways that are not merely additive. ${ }^{39}$ Representational essentialism is at odds with the positions antiessentialists have advocated.

As we have seen, not all anti-essentialist arguments target the same components of essentialism. Moreover, working to undermine one component of representational essentialism is consistent with accepting another. For instance denying that there is an underlying biological essence to a kind is consistent with accepting there is a kind with inductive potential and exclusive stable membership. Since anti-essentialist arguments have targeted both the essence and kind components of essentialism, I focus on projects with these broader aims for the time being. In Section IV I consider ways that an ameliorator might avoid pernicious forms of essentialism without avoiding essentialism full stop.

Consider an ameliorative project with broad anti-essentialist aims. This project, like all ameliorative projects, is aimed at changing how we talk and think as a partial means to change how we behave. It might also have metaphysical aspirations. For instance, changes in how we represent or classify might have effects on behavior, expectations, and on social kinds themselves. ${ }^{40}$ Insofar as

\footnotetext{
${ }^{37}$ Elizabeth Spelman, Inessential Woman (Boston: Beacon Press, 1988).

38 Grillo, “Anti-Essentialism and Intersectionality,” 19.

39 bell hooks, Feminist Theory: From Margin to Center (Boston: South End Press, 1981); Kimberlé Williams Crenshaw, "Demarginalizing the Intersection of Race and Sex: A Black Feminist Critique of Antidiscrimination Doctrine, Feminist Theory and Antiracist Politics," University of Chicago Legal Forum (1989): 139-167; Kimberlé Williams Crenshaw, "Mapping the Margins: Intersectionality, Identity Politics, and Violence against Women of Color," Stanford Law Review 43, no. 6 (1991):1241-99; Patricia Hill Collins, Black Feminist Thought: Knowledge, Consciousness and the Politics of Empowerment (New York: Routledge, 1990); María C. Lugones and Elizabeth V. Spelman, "Have We Got a Theory for You! Feminist Theory, Cultural Imperialism, and the Demand for "The Woman's Voice"," Women's Studies International Forum 6, no. 6 (1983): 573-81.

${ }^{40}$ Ian Hacking, "The Looping Effects of Human Kinds," in Symposia of the Fyssen Foundation. Causal cognition: $A$ Multidisciplinary Debate, eds. Dan Sperber, David Premack, and Ann James Premack (New York: Clarendon Press/Oxford University Press, 1995), 351-394; Ian Hacking, The Social Construction of What? (Cambridge, MA: Harvard University Press, 2000); Sally Haslanger, "Ontology and Social Construction," Philosophical Topics 23, no. 2 (1995): 95-125; Rachel Cooper, "Why Hacking is Wrong about Human Kinds," The British Journal for the Philosophy of Science 55, no. 1 (2004): 73-85; Ron Mallon, The Construction of Human Kinds (Oxford: Oxford University Press, 2016).
} 
either the existence or nature of a social kind depends on our representations, changes in representations can have metaphysical effects. ${ }^{41}$ In the first instance, however, anti-essentialist ameliorative projects are aimed at undermining representational essentialism. For an ameliorative project (rather than a theory in social metaphysics) to meet its socio-political anti-essentialist ends, representational essentialism must be combatted. Let's now turn to further support for the view that nouns trigger representational essentialism.

\section{The Distinction Between Nouns and Adjectives}

Data from psychology and semantics show that nouns and adjectives elicit a widespread difference in essentializing. Much of the focus in the current literature has been on generics like 'women are emotional.'42 Here I motivate a broader view-nouns as a lexical category essentialize in ways that adjectives do not. In order to keep our inquiry focused, I center our examination on predicate adjectives and predicate nominals (like in examples $1 \mathrm{~b}-4 \mathrm{~b}$ above). In addition to allowing for more careful tests to be run, the particular case study is interesting as the distinction between predicate adjectives and nominals has overwhelmingly been elided by semantic theories. 43 After presenting data I motivate that the evidence for a difference between predicate adjectives and nominals extend to adjectives and nouns more generally.

\footnotetext{
41 There is extensive debate about the ways and extent to which social kinds depend on representations. Some hold that representations or collective acceptance are crucial to constructing social kinds. See, e.g., Mallon, The Construction of Human Kinds; John Searle, Making the Social World: The Structure of Human Civilization (Oxford: Oxford University Press, 2010). Others argue that at least some social kinds can exist without representations of that kind itself or in ways that do not involve mind-dependence at all. See, e.g., Amie Thomasson, "Social Entities," in Routledge Companion to Metaphysics, eds. Robin Le Poidevin, Peter Simons, Andrew McGonigal, and Ross P. Cameron (London: Routledge 2009), 545-554; Muhammad Ali Khalidi, “Three Kinds of Social Kinds," Philosophy and Phenomenological Research 90, no. 1 (2015): 96-112; Rebecca Mason, "Against Social Kind Anti-Realism," Metaphysics 3, no. 1 (2020). The degree to which projects that successfully ameliorate concepts/expressions will have metaphysical effects depends on what relationships hold between representations and kinds. For further relevant discussion see Ásta [published under "Ásta Sveinsdóttir"], "Social Construction," Philosophy Compass 10, no. 12 (2015): 884-892; Rebecca Mason, "The Metaphysics of Social Kinds," Philosophy Compass 11, no. 12 (2016): 841-850.

${ }^{42}$ Foster-Hanson et al., "How Does Generic Language Elicit Essentialist Beliefs?”; Rhodes, et al., "Cultural Transmission of Social Essentialism."

43 Ariel Cohen, "Generics and Mental Representations," Linguistics and Philosophy 27 (2004): 529-556; Kai von Fintel and Irene Heim, Intensional Semantics. (Lecture Notes, 2011); Irene Heim and Angelika Kratzer, Semantics in Generative Grammar (Malden, MA: Blackwell, 1998); Richard Montague, “The Proper Treatment of Quantification in Ordinary English,” in Approaches to Natural Language, eds. Jaakko Hintikka, Julius Moravcsik, and Patrick Suppes (Dordrecht, Holland: Reidel 1973), 221-242.
} 


\section{IIa. Evidence from Cognitive Psychology}

Experiments in cognitive and developmental psychology reveal that expression types can affect the extent to which people engage in essentialist thinking. When a noun rather than adjective is used, both children and adults draw more robust inferences and judge features to be more inheritable, persistent, and explanatory. Using nouns to label, rather than adjectives to describe, can have significant cognitive effects. Psychologists Bigler and Liben hypothesize that "the mere act of categorization triggers processes involved in the construction of social stereotypes."44 Gelman argues "language that is used to express membership in a category can influence children's judgments about that category" and that "[c]ount nouns imply that a category is relatively more stable and consistent over time and contexts than adjectives or verbal phrases." 45 While she takes representational essentialism to likely be ingrained in human cognition, using nouns strengthens essentialist thinking.

Studies have shown that children draw richer inferences in conditions when a noun is used (e.g., 'bird') than in conditions when adjectives are used (e.g., 'sleepy').46 In a study involving 2-yearold children, Gelman and Coley found that children were more apt to rely on nominal labels than superficial similarities in appearance to draw inferences about atypical looking members of a kind (e.g., dodo birds, pterodactyls). ${ }^{47}$ For example, when a child was shown a picture of a pterodactyl and told "This is a dinosaur" they were more apt to think it would share properties with other dinosaurs, even though it appeared to be much more similar to a bird. In trials without any label, children inferred that the pterodactyl was likely to be similar to birds. In contrast using adjectival labels like "sleepy" and "wide awake" did not elicit the same inferential behavior. Rather, in these conditions children relied on similar appearances as they did in the no label cases.

\footnotetext{
44 Rebecca S. Bigler and Lynn S. Liben, “Developmental Intergroup Theory: Explaining and Reducing Children’s Social Stereotyping and Prejudice,” Current Directions in Psychological Science. 16, no. 3 (2007): 162-166, 164.

45 Gelman, "Psychological Essentialism in Children,” 407.

46 Susan A. Gelman and Ellen M. Markman, "Young Children's Inductions from Natural Kinds: The Role of Categories and Appearances," Child Development 58 (1987): 1532-1541; Susan A. Gelman and John D. Coley, "The Importance of Knowing a Dodo is a Bird: Categories and Inferences in 2-year-old Children," Developmental Psychology 26 (1990): 796-804; Sandra R. Waxman, "Linguistic Bias and the Establishment of Conceptual Hierarchies: Evidence from Preschool Children,” Cognitive Development 5 (1990): 123-150; Vikram K. Jaswal and Ellen M. Markman, “Children's Acceptance and Use of Unexpected Category Labels to Draw Non-obvious Inferences," in Proceedings of the 24th Annual Conference of the Cognitive Science Society, eds. Wayne D. Gray and Christian Schunn (Mahwah, NJ: Erlbaum, 2002), 500-505; Susan A. Graham, Cari S. Kilbreath, and Andrea N. Welder, "Thirteen-month-olds Rely on Shared Labels and Shape Similarity for Inductive Inferences,” Child Development 75 (2004): 409-427.

47 Gelman and Coley, "The Importance of Knowing a Dodo is a Bird.”
} 
To test the differences in the strength of import of predicate nominals and predicate adjectives, Markman and Smith ran studies involving college students. 48 In their studies, they presented participants with pairs like 5 .

5. a. John is liberal.

b. John is a liberal.

Participants were asked to choose which of the two seemed "to be a stronger or more powerful statement about the person" and rate the difference on a scale. They were then asked to write down "any ideas they had about what accounted for the differences they perceived." 49 Overall, the statements with predicate nominals were chosen far more than those with predicate adjectives as the stronger of the pair. In describing the difference participants reported that the adjective seemed like just "one trait of the individual" and like a "causal observation" that held "sometimes but not always." 50 In contrast students reported that the nominal construction "implies [the trait is] a major part of his life", is "like a name tag," and involves "admittance to a select ... group."51

To test whether the nominal form or specific lexical knowledge is eliciting robust inferential judgments, Gelman and Heyman conducted experiments using novel predicate nominals. ${ }^{52}$ They tested children to determine whether judgments about persistence and resilience, were affected by nominal and habitual verbal constructions. They used examples like in 6 .

6. a. Rose eats carrots whenever she can.

b. Rose is a carrot-eater.

Children took carrot-eating to be more persistent and resilient (e.g., maintained even with family disapproval) when nominals as in $6 \mathrm{~b}$, rather than habituals as in 6 a were used. Since carrot-eater is not a noun that the children were previously familiar with, they argued that the data show "children were not retrieving rote meanings, but rather made use of a general rule that they applied to these novel noun phrases." 53

\footnotetext{
48 Studies reported in Markman, Categorization and Naming in Children, 123-125. For similar studies see Andrea Carnaghi, Anne Maass, Sara Gresta, Mauro Bianchi, Mara Cadinu, and Luciano Arcuri, "Nomina Sunt Omina: On the Inductive Potential of Nouns and Adjectives in Person Perception," Journal of Personality and Social Psychology 94 (2008): 839-859.

49 Markman, Categorization and Naming in Children, 123.

50 Ibid.

51 Ibid.

52 Susan A. Gelman and Gail D. Heyman, "Carrot-Eaters and Creature-Believers: The Effects of Lexicalization on Children's Inferences About Social Categories," Psychological Science 10, no. 6 (1999): 489-493.

53 Ibid., 491.
} 
Experimental evidence shows that nouns have systematic effects on the judgments and inferences children and adults are apt to draw about category members. Data also reveal that the differences in inferential judgments from predicate nominals and predicate adjectives that we relied on in the pairs in 1-4 are robust and, importantly, that the phenomenon is productive. To further support the distinction, in the next two sections I consider linguistic data involving predicate adjectives and predicate nominals.

\section{IIb. Contrastive Data}

First, let's consider the way a predicate adjective or predicate nominal might be used in a conversational exchange like in 7.

7. A: Is Linnea a blonde?

B: Well, she is blonde, but I wouldn't say she is a blonde.

In the exchange, B avoids an outright yes- or no-answer. Instead, she hedges using "well" and noting that she wouldn't use the nominal "a blonde" to label Linnea (and perhaps also the stronger claim that she wouldn't use it to label anyone at all). If B were to agree outright, it seems she would commit to something stronger than that Linnea is flaxen-haired, for instance that there is some nature blonde people share or that Linnea has certain stereotypical qualities that are associated with the group. Note also, that if $\mathrm{B}$ were to give an explicit negative answer, $\mathrm{B}$ would be committing herself to the claim that Linnea is not blonde. If Linnea is blonde and B is being cooperative, she would not want to give an explicit negative answer. In contrast, the conversational pattern in 8 does not require the same hedging in order to avoid essentializing, categorizing, or generalizations.

8. A: Is Linnea blonde?

$\mathrm{B}$ : Yes, she is.

In fact, if B were to follow up in 8 with "but I wouldn't say she is a blonde," it would sound fairly odd, as that was not at issue given A's utterance.

Outside of conversational exchanges, data show that constructions involving predicating an adjective of a subject while, in the same breathe, denying that the nominal holds of them are felicitous.

9. George is conservative, but not a conservative. ${ }^{54}$

\footnotetext{
54 William F. Buckley, Jr. described George W. Bush in this way. Another similar example can be found in a biography of the British Cold War spy, Jeremy Wolfenden. Sebastian Faulks, The Fatal Englishman (London: Vintage Books, 1997).

There it is reported that a schoolmate told him to "Be queer, but not a queer". Idid., 222.
} 
In contrast, attributing and then denying an adjective or a nominal as in 10-11 sounds at least somewhat infelicitous if not straightforwardly contradictory.

10. \# George is conservative, but not conservative.

11. \# George is a conservative, but not a conservative.

\section{IIc. Cancellation Data}

Finally let's consider the extent to which inferences from predicate nominals can be explicitly canceled. The speaker of 12 is apparently trying to cancel something with the second clause.

12. He's a queer, but I like queers!

They might be attempting to cancel the inference between being queer and meeting some stereotypes, or between having some negative features because one is queer, but the inference from the first clause of 12 to there being a group that has persistent explanatory qualities is not canceled. That is, the speaker of 12 is not denying that there is a category or kind that is a stable locus for inferential judgments. One can imagine the speaker following up 12 with a list of features they take queer folks to share, but which they take to be positive. Suppose one explicitly attempts to cancel the inference that there is a group one is categorizing the person in as in 13.

13. ?? She's a female, but females are not a group with shared explanatory characteristics. 13 is strange, in part, because the first clause strongly elicits the judgment that females do share some persistent explanatory traits. In some contexts a variant of 13 might be more acceptable. For instance, suppose we're in a context in which job candidate's are being discussed. Someone is speaking about candidates as "females." Someone might express frustration and utter 13 or 13 '.

13'. ?? She's a female, but there is nothing more to being a female than being female. In some contexts cancellation might be possible, but it is not easy. .5

The evidence considered in IIa-IIc shows that the distinction between predicate nominals and predicate adjectives is robust. ${ }^{56}$ In general, sentences of the form 'c is an F' elicit the inference that there is a kind or group, Fs, with shared, stable, and explanatory features. I'll call inferences of the form 'Fs share further traits that are explanatory and stable' essentializing inferences. Nouns vary widely in the specific features, stereotypes, negative/positive valence, and so on that are brought to mind. There are clearly differences in saying someone is a doctor, a New Yorker, or a Black. Yet, each is plausibly stable and is taken to have inductive and explanatory potential. While we do not take New

\footnotetext{
55 Thanks to Matt Teichman for this example.

${ }^{56}$ For further evidence and development of a semantics for these constructions, see Katherine Ritchie, "Essentializing Inferences" (manuscript).
} 
Yorkers to be a biological category, many do take them to be fast walkers and to overpay for housing. The claim being made here is that the use of nouns encourages representational essentialist thinking in at least this general form. We infer that there is more to being an $F$ than just being F.57

While I have focused primarily on nouns and adjectives in predicate position, much of the data supports the stronger view that nouns as a lexical category are poised to essentialize in a way that adjectives are not.58 Data from cognitive and developmental psychology, including many of the studies reported on in IIa, do. Generics like 14 and 15 support the broader view as well.

\section{Women are nurturing.}

15. Pigs like mud.

Quantified statements like in 16 and 17 also seem to reinforce essentialist thinking. They too involve labeling people as members of social groups

16. A queer wrote the best paper in my class.

17. Ten blondes are in that store.

Data show that statements with high proportion quantifiers like in 18 also elicit essentialism. ${ }^{59}$

\footnotetext{
57 Some adjectives can represent features as essential (e.g., human, intelligence). So, one might ask, what are nouns really doing? My claim is not that language essentializes if and only if it involves nouns. Rather the claim is that nominals elicit stronger judgments of persistence, resilience, stability, explanatoriness, coherence, and so on. Given world knowledge, some adjectives might lead to very high judgments on these features as well. Yet, even in cases in which an adjective might be taken to be essential and to have a biological basis, nominals convey something stronger and more stable. For instance, consider $\mathrm{i}$ and ii.

i. A: He's idiotic.

B: ?? No, he's just an idiot.

ii. A: He's an idiot.

B. No, he's just idiotic.

The felicity differences can be explained by the fact that nouns as a lexical category are poised to essentialize. Thanks to Uriah Kriegel for pressing me on this point.

${ }^{58}$ Here I have also focused only on English data. Not all languages include articles, like the indefinite article $a$ that marks the difference in surface form between English predicate adjectives and predicate nominals. Distinct lexical categories for nouns and adjectives are, however, widely held to be universal amongst human languages. In languages without articles, different data would be needed to reveal the divergent effects of nouns and adjectives. For example, see Sylvie Graf, Michal Bilewicz, Eerika Finell, and Daniel Geschke, "Nouns Cut slices: Effects of Linguistic Forms on Intergroup Bias," Journal of Language and Social Psychology, 32, no. 1 (2013): 62-83. In these studies, Graf et al. examined the effects using nouns or adjectives for nationality had on inter-group bias. To allow for similar conditions across subjects, some of whom spoke languages with articles (e.g., German), some of whom spoke languages without articles (e.g., Finnish), they used stimuli which used different punctuation. For instance, the nationality term must be interpreted as a noun in stimuli of the form a Finn, a painter (in Finnish: suomalainen, taidemaalari) while an adjectival interpretation is required in forms like a Finnish painter (in Finnish: suomalainen taidemaalar). They found that expressing nationality with a noun augmented in-group bias more than expressing it with an adjective. I thank an anonymous associate editor for pressing me on this point.

${ }^{59}$ Elena Hoicka, Jennifer Saul, Eloise Prouten, Laura Whitehead, and Rachel Sterken. 2018. "Language Signalling High Proportions, Not Just Generics, Leads to Essentializing for Novel Social Kinds,” (under review). doi:10.31234/osf.io/ xe6sj.
} 
18. Many / Most Zarpies love to eat flowers.

Moreover, Leslie and Gelman have also found that quantified statements are often recalled as generics, further bolstering the idea that the use of nouns bound by quantifiers essentialize. ${ }^{60}$

Essentialist thinking is not elicited to the same degree by each and every noun. Evidence shows that nouns for natural kinds and social kinds tend to license stronger inferences than those for artifacts. ${ }^{61}$ There are also variations in the extent to which we essentialize when presented with nouns for human kinds. For instance, Newman and Knobe argue that we represent social categories like scientists and friends, but not waiters and bus drivers, as having essences. ${ }^{62}$ The general form of essentializing inferences allows for significant variability. It does not require that one have robust stereotypes, negative affect toward the kind, or that one posit a biological essence. Rather, it involves nouns being used for categories that are viewed as kinds and that kinds are taken to have shared, stable, and explanatory features. There is good psychological and linguistic evidence for a close connection between nouns and essentializing.

We now have the first two components needed for my argument. We have homed in on our target class of ameliorative projects_-anti-essentialist projects that aim to ameliorate nouns. We also have evidence showing a robust connection between nouns and representational essentialism. Next I turn to the problem these ameliorative projects must confront.

\section{The Effects of Representational Essentialism on Ameliorative Projects}

The data in the last sections showed that nominals and their conceptual correlates elicit essentialist thinking. They signal that there is a kind that is cohesive, homogenous, has inductive potential, and so on. The form of the essentializing inferences I suggested was general-'Fs share further traits that are explanatory and stable.' Changing the content of a particular expression, won't change its connection to representational essentialism. Further, we saw that the pattern is productive (e.g., in the example with carrot-eater). It does not rely on particular stereotypes or characteristics. Rather, it is the use of the nominal itself that underpins essentializing. In asking us to revise the content of expressions or concepts while retaining nominal/labeling terminology, we will continue to be poised to essentialize.

\footnotetext{
60 Sarah-Jane Leslie and Susan A. Gelman, “Quantified Statements are Recalled as Generics,” Cognitive Psychology 64 (2012): 186-214.

${ }^{61}$ Gelman, The Essential Child.

${ }^{62}$ Newman and Knobe, "The Essence of Essentialism."
} 
The sorts of representational devices ameliorators focus on make the problem more pressing. Using nouns to label someone as a woman or a Black person or a queer or ... can underscore the idea that that is what the person is. That being a woman or a Black person or ... underlies the person's very nature and explains their aptitudes, preferences, and behavior. This can undermine the person's agency; it can dehumanize. It also brings to salience membership in a socially subordinate group, perhaps serving to motivate further domination or cruelty. ${ }^{63}$

Note that the worry I am advancing is not the general claim that identity-based political projects essentialize. Many have argued that appeals to identity categories are essentialist, exclusionary, inherently tied to oppression, and, consequently, that appealing to such categories is antithetical to achieving social justice aims. For instance, Butler argues “the category of 'women', the subject of feminism, is produced and restrained by the very structures of power through which emancipation is sought." 64 Bettcher argues that some "radical feminists ... lapse into essentialist appeals to chromosomes as the invariant determinants of sex." 65 Some theorists take these essentialist worries to doom identity politics. ${ }^{66}$ Others defend identity-based projects arguing that standpoints need not essentialize, that anti-essentialist intersectionality can be promoted, and that identity politics can involve transformative and resistant identities. ${ }^{67}$ The argument I am making here is focused specifically on ameliorative projects aimed at changing our thought and speech. The claim

${ }^{63}$ Kate Manne, “Humanism: A Critique,” Social Theory and Practice 42, no. 2 (2016): 389-415.

${ }^{64}$ Judith Butler, Gender Trouble: Feminism and the Subversion of Identity (New York: Routledge, 1990), 2.

65 Talia Mae Bettcher, "Intersexuality, Transgender, and Transsexuality," in The Oxford Handbook of Feminist Theory, eds. L. Disch and M. Hawkesworth (New York: Oxford University Press, 2015), 407-427, 422.

66 Wendy Brown, States of Injury: Power and Freedom in Late Modernity (Princeton: Princeton University Press, 1995); Appiah, The Lies that Bind.

${ }^{67}$ Linda Alcoff, "Who's Afraid of Identity Politics?," in Reclaiming Identity: Realist Theory and the Predicament of Postmodernism, eds. P.M.L. Moya and M.R. Hames-García (Berkeley: University of California Press, 2000), 312-44; Bettcher, "Intersexuality, Transgender, and Transsexuality"; Patricia Hill Collins, "Learning from the Outsider Within: The Sociological Significance of Black Feminist Thought," in The Feminist Standpoint Theory Reader: Intellectual and Political Controversies, ed. Sandra G. Harding (New York: Routledge, 2004), 103-126; Sharon Crasnow, "Feminist Anthropology and Sociology: Issues for Social Science," in Philosophy of Anthropology and Sociology, eds. Stephen P. Turner and Mark J. Risjord (Amsterdam: Elsevier, 2007), 755-790; Donna Haraway, "Situated Knowledge: The Science Question in Feminism and the Privilege of Partial Perspective. Feminist Studies 14, no. 3 (1988): 575-599; Sandra Harding, "A Socially Relevant Philosophy of Science? Resources from Standpoint Theory's Controversiality," Hypatia 19 (2004): 25-47; Susan Hekman, “Truth and Method: Feminist Standpoint Theory Revisited,” Signs 22, no. 21 (1997): 341-365; Grillo, "Anti-Essentialism and Intersectionality"; Ann Ferguson, "Resisting the Veil of Privilege: Building Bridge Identities as an Ethico-Politics of Global Feminisms," Hypatia 13, no. 3 (1998): 95-113; Katherine Ritchie, "Does Identity Politics Reinforce Oppression? Philosophers' Imprint (forthcoming); Stone, "Essentialism and Anti-Essentialism"; Allison Weir, "Global Feminism and Transformative Identity Politics,” Hypatia 23, no. 4 (2008):110-133; Iris Marion Young, Justice and the Politics of Difference. (Princeton: Princeton University Press, 1990); Iris Marion Young, "Gender as Seriality: Thinking about Women as a Social Collective," Signs 19, no. 3(1994): 713-738. 
is that certain sorts of representational devices-nouns and their conceptual correlates-pose a problem for anti-essentialist ameliorative projects. Let's turn to spelling out the worry in more detail.

Return to the example of a theorist engaged in an anti-essentialist ameliorative project focused on gender. Perhaps in the throes of theorizing the conceptual engineer can avoid essentialism. In the context of offering her theory, some of the theorist's uses of nouns may be metalinguistic. ${ }^{6}$ For example, the theorist might utter 19, in part aiming to advocate for a trans inclusive meaning of woman.

19. Laverne Cox is a woman.

Her theorizing here explicitly focuses on which individuals fall in the extension of a term or concept. She might engage in metalinguistic negotiation with someone who rejects $19 .{ }^{69}$ She could justify the meaning she advocates by, for example, appealing to normative considerations, noting that the meaning correctly classifies many individuals and subkinds, and by explaining away cases that violate what some take to be common sense.

The theorist might also explicitly work to cancel essentializing inferences. Recall the cancellation data we considered above (repeated below).

13. She's a female, but females are not a group with shared explanatory characteristics.

13'. She's a female, but there is nothing more to being a female than being female.

The second clauses in 13 and 13' sound significantly more natural when considered in the context of an ameliorative project.

Cases of what Sterken calls communicative disruptions provide another opportunity for the ameliorator to push for revision. ${ }^{70}$ Sterken considers a case like the following. Suppose that an ameliorator begins using and interpreting woman to in the way Haslanger proposed, but with the full understanding that this will lead to misunderstanding and misinterpretation. In some context she might say "we should work to eradicate women!" with the intention of conveying that we should attempt to eliminate gender-based subordination. As Sterken puts it, her utterance involves an attempt to "disrupt the interpretive common ground so as to affect metalinguistic reflection and

\footnotetext{
${ }^{68}$ Chris Barker, “The Dynamics of Vagueness," Linguistics and Philosophy 25, no. 1 (2002):1-36; David Plunkett and Timothy Sundell, "Disagreement and the Semantics of Normative and Evaluative Terms," Philosophers' Imprint 13, no. 23(2013): 1-37.

${ }^{69}$ Plunkett and Sundell, "Disagreement and the Semantics of Normative and Evaluative Terms."

${ }^{70}$ Rachel K. Sterken, “Linguistic Interventions and Transformative Communicative Disruption," in Conceptual Engineering and Conceptual Ethics, eds. Alexis Burgess, Herman Cappelen, and David Plunkett (Oxford: Oxford University Press, 2020), 417-424.
} 
reconstruction on the part of her interlocutor.' 71 The disruptor's usage of woman is meant to encourage metalinguistic rumination that will contribute to linguistic transformation. The speaker could have used language that would not have been disruptive. For instance, she might have said "we should work to eradicate gender-based oppression!” In opting for the disruptive utterance, the speaker's aim is, at least in part, to revise or transform the meaning of woman. The speaker has intentions that are metalinguistic. She is encouraging her interlocutors to engage at the metalinguistic level. When using expressions metalinguistically and when speakers engage in communicative disruptions, essentializing inferences might be canceled or avoided.

I have doubts that even the most committed conceptual engineer with their, ahem, human psychology can completely avoid representational essentialism. By way of comparison, consider work on the linguistic contributions of slurs. Even when slurs are mentioned in the act of theorizing they are often taken to be offensive and to convey something negative. This judgment is had even by many philosophers and linguists, people who certainly recognize the difference between use and mention. If mentioning a slur has significant shared cognitive effects with the use of a slur, mentioning or engaging in metalinguistic negotiation with an expression that essentializes might as well. Nevertheless, even if we suppose that the theorist and her interlocutors avoid essentializing while they are actively engaged in conceptual engineering, this is not sufficient to show that ameliorative projects can meet their anti-essentialist aims.

The success of ameliorative projects requires ordinary, not just metalinguistic, usage to accord with ameliorated meanings. For an ameliorative project to achieve its anti-essentialist aims it needs to help a wide range of people avoid assuming there is an underlying essence of a social category. As Haslanger stated the semantic component involves "asking us to use an old term in a new way." 72 If $u s$ only refers to theorists, it is dubitable that much social progress will be made. An ameliorative project is not successful if it merely allows the theorist, the committed reader, or those engaged in metalinguistic negotiation to avoid essentializing while engaged in actively engaged in these sorts of projects.

In offering up new definitions, the conceptual engineer might get us to think in a different way while considering their theory or reflecting on how our language ought to be. Yet, once we begin using terminology with revised meanings, we essentialize anew. Even if, we might have been inclined to say, the anti-essentialist ameliorative project is successful, we will continue to essentialize.

\footnotetext{
71 Ibid., 421.

72 Haslanger, "Gender and Race”, 48.
} 
Even when they "succeed," it seems ameliorative projects that involve nouns fall back into essentialism's clutches.

If ameliorative projects for nominals and their conceptual correlates fail to avoid essentializing, a more general worry also comes to salience. Essentializing is connected to stereotyping and prejudice. The extent of the correlation and whether it exists across all social categories is still being investigated. ${ }^{73}$ Insofar as there is a robust and widespread connection, ameliorators should be even more worried about language that elicits essentializing inferences. For instance, Leslie argues "the use of generics or even simply labels may communicate that these are essentializable groups, and so open the door to prejudice." 74 At their inception, ameliorative projects are aimed at undermining oppression. If essentializing is closely connected to prejudice, the general social justice aims of ameliorative projects (i.e., even those not focused on anti-essentialism) are also undermined by continuing to use nominals.

\section{What is the Would-Be Ameliorator to Do?}

Given the aim to uphold anti-essentialism outside of the limited contexts of theorizing and worries about the connection between essentialism and prejudice, a would-be ameliorative might decide to abandon ameliorative projects altogether. Recall that ameliorative projects involve advocating for the use of terms/concepts for social-political ends. The arguments in the last section could be taken to show that what is needed (at least when considering ameliorative projects that involve nouns and have anti-essentialist aims) is an elimination strategy. On this strategy the would-be ameliorator aims to eliminate nouns in favor of adjectives or verbs. Projects like these are still in the realm of conceptual engineering. ${ }^{75}$ For instance Burgess and Plunkett suggest that eliminativism be used "for the distinctly normative, representational view that we ought to stop using a given term or concept. Thus construed, eliminativism is a position within conceptual ethics." ${ }^{76}$ In adopting an eliminativist strategy, the would-be ameliorator gives up on an ameliorative project, but she does not give up on

\footnotetext{
${ }^{73}$ Nick Haslam, Louis Rothschild, and Donald Ernst, "Are Essentialist Beliefs Associated with Prejudice?," British Journal of Social Psychology 41, no. 1 (2002): 87-100; Nick Haslam and Sheri R. Levy, "Essentialist Beliefs About Homosexuality: Structure and Implications for Prejudice," Personality and Social Psychology Bulletin 32, no. 4 (2006): 471-485; Noyes and Dunham, "Separating Kindhood from Naturalness."

${ }^{74}$ Leslie, “The Original Sin of Cognition," 418.

75 Burgess and Plunkett, "Conceptual Ethics II"; Cappelen, Fixing Language.

76 Burgess and Plunkett, “Conceptual Ethics II,” 1103.
} 
conceptual engineering across the board. Perhaps an eliminative, rather than revisionary, form of conceptual engineering is a better method of conceptual engineering for those with social justice aims.

There are advocates for social-political eliminativist projects. Leslie suggests that avoiding generics and labels might be a way to avoid essentializing and limit prejudice. ${ }^{77}$ She states "reducing the use of labels and generics for racial, ethnic, and religious groups may reduce the extent to which children grow up essentializing these groups."78 Her view coheres with what the recommendation from the CDC and some disability rights activists that person-first language be used when referring to people with disabilities. For instance, the CDC recommends the use of person with epilepsy over epileptic. ${ }^{79}$ Dembroff and Wodak argue that we should not use gendered pronouns. One of their motivations is to avoid essentialism. ${ }^{80}$ The would-be ameliorator might emulate these projects and argue that nouns (or nouns for social groups and social roles) should be eliminated.

In some instances, eliminativism might be the best option to meet a given social-political aim. Perhaps some nouns should be eliminated in favor of adjectives. This is one option that the conceptual engineer should keep in her arsenal. ${ }^{81}$ Yet, there are both normative and implementation worries that undermine a wholesale adoption of an eliminativist response to the problem. Let's consider normative worries first.

In some cases other factors might outweigh the anti-essentialist aims of a social justice project. For instance, many disability rights theorists have rejected person-first language and have advocated for identity-first language (e.g., autistic person) or nominals (e.g., an autistic or Aspie). For instance, Sinclair argues that person-first language wrongly suggests that disability is separable, transient, and not central or important to the person's identity. ${ }^{82}$ He argues against each of these and for identity-first locutions that emphasize the centrality and importance of disability to personal identity. Moreover, disability rights theorists argue that person-first language wrongly implies that

\footnotetext{
77 Leslie, "The Original Sin of Cognition.”

78 Ibid., 420.

${ }^{79}$ See https://www.cdc.gov/ncbddd/disabilityandhealth/pdf/disabilityposter photos.pdf

${ }^{80}$ Robin Dembroff and Daniel Wodak, "He/She/They/Ze," Ergo: An Open Access Journal of Philosophy 5 (2018).

81 There is another way eliminativism might be paired with ameliorative projects. An ameliorative project like Haslanger's might be aimed at revising language and concepts as part of a strategy to eliminate (in a metaphysical sense) a social category. Once the social category is destroyed, the noun for the category might be likewise eliminated. In this case a project of language revision (i.e., an ameliorative project) is followed by a project of conceptual/linguistic elimination. I thank an anonymous referee for suggesting this connection.

82 Jim Sinclair, “Why I Dislike "Person First” Language,” Autism Network International 2, no. 1 (1999/2013).
} 
disabilities like autism are negative and to be hidden, rather than identities to be affirmed and validated. ${ }^{83}$

If nouns are to be avoided, then generic constructions with nouns in subject position ought to be avoided as well. But, several philosophers have argued that the benefits of certain social generics might outweigh the potential harms of essentializing. Narayan argues that not all generics convey cohesiveness or homogeneity. For instance she argues that a generic like women are discriminated against in public and private spheres in myriad ways does not entail "the absence of variations within and across national contexts in the form of human rights violations that confront different groups of women." 84 Generics like this one might be useful in political contexts. Other generics such as boys like pink too might be helpful in combatting certain norms. ${ }^{85}$ Since generics often require correlations that are stronger than mere statistical accident, social generics might also be the best linguistic tools we have for accurately describing structural forms of oppression. ${ }^{86}$ Insofar as accurate descriptions are useful for successfully combatting oppression, we would have good reason to use social generics. This suggests that nouns, even in the form of generic generalizations, can positively contribute to social justice projects.

More generally, nominals provide important resources that increase the expressive potential of a language. ${ }^{87}$ For instance, expressing laws aimed at mitigating the oppression of groups that have been historically marginalized involves reference to categories of people, not just individual people. Concepts and expressions for social categories allow for us to identify, explain, and hopefully change forms of oppression. 88

\footnotetext{
83 Sinclair, "Why I Dislike"; Emily Ladau, "What Should You Call Me? I Get to Decide: Why I'll Never Identify with Person-First Language,” in Criptiques, ed. Caitlin Wood (San Bernardino, CA: May Day Publishing, 2014), 47-56.

${ }^{84}$ Narayan, “Essence of Culture,” 103.

85 Jennifer Saul, “Are Generics Especially Pernicious?,” Inquiry: An Interdisciplinary Journal of Philosophy (2017):1-18.

86 Katherine Ritchie, “Should We Use Racial and Gender Generics?,” Thought 8, no. 1 (2019): 33-41.

${ }^{87}$ The additional expressive power second-order logic has over first-order logic supports this claim in an abstract way. For arguments that a language with nouns for numerals allows for finite, rather than infinite, expressions of statements, see Stephen Yablo, "The Myth of the Seven," in Fictionalism in Metaphysics, ed. Mark Eli Kalderon (Oxford: Oxford University Press, 2005), 88-115. For a pragmatic approach to conceptual ethics and consideration of various conditions, including expressive power, that are relevant in determining what terms to construct or continue to use, see Amie Thomasson, "A Pragmatic Method for Conceptual Ethics," in Conceptual Engineering and Conceptual Ethics, eds. Alexis Burgess, Herman Cappelen, and David Plunkett (Oxford: Oxford University Press, 2020), 435-458.

${ }^{88}$ For discussion of the sorts of concepts might be needed to meet these varied aims, see Ingo Brigandt and Esther Rosario, "Strategic Conceptual Engineering for Epistemic and Social Aims," in Conceptual Engineering and Conceptual Ethics, eds. Alexis Burgess, Herman Cappelen, and David Plunkett (Oxford: Oxford University Press, 2020), 100-124.
} 
Even if the eliminativist strategy could be justified on political and ethical grounds, we should not be overly optimistic about its potential for success. On the eliminativist strategy nouns for social groups and social roles are to be eliminated and replaced by expressions in another lexical category. To make the case concrete, suppose they are replaced by adjectives. Saul argues that expressions that begin their lives as adjectives, are apt to begin to function as labels over time. ${ }^{89}$ For instance she notes that the attempt to replace moron and idiot with mentally retarded person was unsuccessful. The adjective became a noun. Moreover, terms that are replacements for negatively valenced terms tend to become pejorative. The way terms for mentally disabled people and stigmatized racial groups have been replaced again and again provide vivid examples.

Instead of abandoning ameliorative projects completely, let's consider a more nuanced response to the problem. With increased nuance we enter murky waters full of complexities and specificities that reveal ways an account will need to balance psychological, moral, social-political, and linguistic factors. The social world and our representations of it are complex. The fact that there is not a simple response (eliminate all nouns!) for the ameliorator should come as no surprise.

To begin to see the shape a strategy for the would-be ameliorator ought to take, let's return to a claim I made about language in II. I argued that broadly speaking nouns are poised to elicit essentializing inferences. I argued that the sorts of inferences nouns as a class elicit are general and non-evaluative. They are of the form 'Fs share further traits that are explanatory and stable.' So, on this view, essentializing itself does not entail stereotyping or prejudiced beliefs. These negative features are not built into the account and additional nominal constructions provide strong reason to doubt the view that they are.

There are many nouns that do not seem to elicit negative inferences. For instance consider the following example.

20. Laura is a doctor.

20 involves attributing kind membership to the subject and an essentializing inference that the kind shares further stable and explanatory features. For instance, in learning that Laura is a doctor, one might infer that she has an M.D., meets with patients, has an obligation to care for her patients, is intelligent, and so on. These features are associated with being a doctor. Yet, an utterance of 20 would not normally imply anything negative. It does not serve to dehumanize Laura or minimize her agency. The lack of negative valence and dehumanization can be explained in part by the nature of different sorts of social kinds and in part by particular attitudes and associations we have with specific kinds.

${ }^{89}$ Saul, "Are Generics Especially Pernicious?”. 
Members of social kinds like doctors, dentists, professors, and point guards have reasonably well defined institutional roles. These might be specified in various ways. For instance, they might be specified in a job description or a hospital code of conduct. An official rulebook for a sports league could define what a player in a particular position is allowed to do and coaches, choreographers, and art critics can design plays, performances, and norms that shape and constrain social roles. The way these kinds depend on social factors like laws and rules is overt; given a bit of reflection it is obvious that there is a dependence relation. ${ }^{90}$ While some aptitudes might be rooted in genetics, we do not take one's profession to be biologically determined. Further, while one's personality, physical aptitudes, and other traits might make one well suited to be a pitcher, musician, or lawyer, we also take there to be considerable volition in determining whether one becomes a member of these social kinds. Certainly it is not wholly up to an individual whether she can join one of these social kinds, but there seems to be an element of choice and an exercise of agency —at least in terms of whether one sets out to join the kind.

Kinds like race, gender, and sexual orientations are different. They are not closely tied to institutionalized roles, like those explicitly set out in employee manuals, even though on many views they do depend on social factors. Gender, racial, ethnic, disability, and other identity kinds depend on social factors in ways that are often covert. ${ }^{11}$ Social kinds like these often appear to be biological or otherwise natural. For instance when theorizing about gender Simone de Beauvoir argues that it can be hard "to measure the enormous extent of social discrimination ... whose moral and intellectual repercussions are so deep in woman that they appear to spring from an original nature." 92 Psychological research shows that even from a young age children think of gender categories as having natural underlying essences. ${ }^{93}$

In taking these kinds to have biological essences, membership is taken to be outside of an agent's control. This may be because membership in these kinds is not volitional (e.g., one is attributed membership in a social kind largely in virtue of what others assume about one's body or ancestry) or because while membership is volitional, many mistakenly believe them to be biological

\footnotetext{
${ }^{90}$ Paul E. Griffiths, What Emotions Really Are: The Problem of Psychological Categories (Chicago: The University of Chicago Press, 1997).

${ }^{91}$ Ibid.; Ron Mallon, "Naturalistic Approaches to Social Construction," in The Stanford Encyclopedia of Philosophy, ed. Edward N. Zalta (Sprint 2019 Edition), https://plato.stanford.edu/archives/spr2019/entries/social-constructionnaturalistic/.

92 Simone de Beauvoir, The Second Sex (New York: Vintage Books, 1949/2010), 35.

93 Rhodes and Gelman, “A Developmental Examination”; Marianne G. Taylor, “The Development of Children's Beliefs about Social and Biological Aspects of Gender Differences,” Child Development 67 (1996): 1555-1571.
} 
and determined by one's genetics. What is important for our purposes is that people often (implicitly) hold that an agent does not have control over whether they are in a racial, gender, or other identity kind.

These considerations and the contrast between cases like 20 and $1 \mathrm{~b}-4 \mathrm{~b}$ point to three correlations between features of a kind and whether it essentializes in ways that are likely to be pernicious.

Biology: The less a noun for a social kind is taken to categorize based on biological features, the less likely it is to perniciously essentialize (e.g., increase prejudice).

Overt Dependence: The more a noun for a social kind is taken to categorize based on features that are taken to depend on social factors, the less likely it is to perniciously essentialize (e.g., increase prejudice).

Agency: The more a noun for a social kind is taken to categorize based on features within an agent's control, the less likely it is to perniciously essentialize (e.g., increase prejudice).

Consider the noun doctor. Since membership in the kind doctors is taken to only minimally depend on biology and is largely taken to be overtly dependent on social factors and involve some volition on membership conditions, it is unlikely to essentialize in a pernicious way. In contrast, since membership in racial and gender kinds are often taken to be biological and are not taken to be overtly social or volitional, labeling someone as a Black or a female is more likely to essentialize in a pernicious way. If these principles are on the right track, when ameliorating nouns the conceptual engineer could work to change content and associated beliefs in order to undermine the view that a kind is biological and augment the view that it is overtly social dependent and volitional.

While the principles outlined above might serve as a good defeasible guide for the ameliorator, they do not provide exceptionless rules. There are two sorts of cases that reveal problems with the constraints. Both point to the need for successful ameliorators to attend to ideologies and broader views on morality and responsibility.

First, people have negative attitudes towards some social kinds that are not represented as biological and are taken to be overtly social and within the volition of an agent. Labels for these kinds could still figure in potentially pernicious forms of essentialist labeling. For instance, while negative attitudes towards doctors are rare, negative attitudes towards bankers, cops, and politicians are somewhat common. Negative attitudes towards felons, prisoners, drug dealers, and sex workers are even more common. For instance, 21 seems to label in a pernicious way.

21. Jordan is a felon. 
Ameliorative projects that are designed with these three principles in mind can still elicit pernicious essentializing effects. ${ }^{94}$

Second, there is evidence that in some cases increasing views that a kind is biological and undermining its membership being volitional elicit less prejudice. For example, Haslam and colleagues found that judgments that being gay is natural were correlated with less prejudice than judgments that being gay was not natural. 95 Given dominance of heteronormative views in U.S. society, the view that one chooses to "violate" social and moral norms may elicit stronger prejudice than the view that homosexuality is biologically determined (one is "born this way"). ${ }^{96}$ Garretson and Suhay found that biological attributions of homosexuality increase support for gay rights. ${ }^{97}$ They also found correlations between political affiliation and acceptance of biological views of sexual orientation. Liberals were more likely to endorse biological views than conservatives.

To give one final example, consider the view that alcoholism is a disease and the view that alcoholism involves a choice. The choice view might be connected with stronger stigma and attributions of personal moral responsible. In contrast, on the disease-model people might be more apt to judge that it is outside of a person's control and, so, hold individual kind members to be less responsible. These cases do not show that the three principles are hopeless. Rather, they point to ways ideology and views of morality, responsibility, and norm-violation interact with essentialist thinking and prejudice.

Let's briefly return to Haslanger's ameliorative project. Recall that she takes gender kinds to be defined in terms of subordination and privilege. These kinds specify roles or positions in social

\footnotetext{
${ }^{94}$ Given variation in attitudes within populations, an expression might perniciously essentialize in one subset of a population while not perniciously essentializing in another. Contextual factors, variations in ideologies, and speaker identities (e.g., is the speaker an in-group member?) will likely have effects on the degree to which essentializing is pernicious.

${ }^{95}$ Haslam, et al., "Are Essentialist Beliefs Associated with Prejudice?.”

96 This is not to say that a biological view of sexual orientation ought to be employed, rather it is to point out a potential exception to the pattern given in Biology. For arguments that a biological view is politically harmful see Carmen M. Butler, "From Victimhood to Agency: A Constructionist Comparison of Sexual Orientation to Religious Orientation," Seattle Journal for Social Justice 4, no. 1 (2005): 147-173; Tia Powell and Edward Stein "Legal and Ethical Concerns about Sexual Orientation Change Efforts," Hastings Center Report 44 (2014): S32-S39; Lisa M. Diamond \& Clifford J. Rosky, "Scrutinizing Immutability: Research on Sexual Orientation and U.S. Legal Advocacy for Sexual Minorities," The Journal of Sex Research 53, nos. 4-5 (2016): 363-391.

${ }^{97}$ Jeremiah Garretson and Elizabeth Suhay, "Scientific Communication about Biological Influences on Homosexuality and the Politics of Gay Rights,” Political Research Quarterly 69, no. 1 (2016): 17-29.
} 
structures. ${ }^{98}$ The account aims to change our views of gender and racial kinds to highlight, and so make more overt, their social structural nature. She also aims to debunk the view that they have biological essences. The account does not, however, take kind membership to be under the volition of a person. Rather, one is a woman if one is subordinated due to perceived or imagined bodily features. These are largely based on external features that are outside of the control of an agent.

While the design of Haslanger's ameliorative project fits with Biology and Overt Dependence, it does not meet Agency. ${ }^{99}$ Whether this is sufficient to avoid stereotyping, prejudice, and oppression is an open question. More research is needed to understand the complex interplay between roles, volition, and naturalness (on the one hand) and pernicious attitudes and actions (on the other).

Ameliorative projects have focused on designing new contents for representational devices. Here I have argued that ameliorators must also attend to the structures or vehicles of representation. Nouns and their conceptual correlates are poised to elicit essentializing inferences in ways that affect whether an ameliorative project can meet anti-essentialist aims. Ameliorative projects are not thereby doomed. Rather the ameliorator can attend to the ways representational vehicles might essentialize in ways that are not pernicious. Ameliorators with anti-essentialist aims can work to engineer terms and concepts by defeasibly following the constraints given by Biology, Overt Dependence, and Agency. The interplay of these constraints and broader moral and political ideologies reveals that there is not a simple set of rules to which the ameliorator can subscribe. But one thing is clear, the structure of our language and thought can significantly affect what we're apt to judge and infer about others and ourselves.

\footnotetext{
${ }^{98}$ For further discussion see Elizabeth Barnes, "Realism and Social Structure,” Philosophical Studies 174, no. 10 (2017): 2417-2433; Katherine Ritchie, "Social Structures and the Ontology of Social Groups," Philosophy and Phenomenological Research 100, no. 2 (2020): 402-424.

${ }^{99}$ For other accounts of the nature of gender kinds also take membership outside of the volition of individual members see Charlotte Witt, The Metaphysics of Gender (Oxford: Oxford University Press, 2011) and Ásta, Categories We Live By: The Construction of Sex, Gender, Race and Other Social Kinds (New York: Oxford University Press, 2018). The role of agency in the nature of social kinds as they currently are and as they ought to be represented in order to best mitigate essentialism might come apart.
} 